\title{
(- OPEN ACCESS \\ Current evidence-based recommendations on investigating children with global developmental delay
}

\author{
Renuka Mithyantha, ${ }^{1}$ Rachel Kneen, ${ }^{2,3}$ Emma McCann, ${ }^{4}$ Melissa Gladstone ${ }^{1,5}$
}

\begin{abstract}
'Department of Developmental Paediatrics, Alder Hey Children's NHS Foundation Trust, Liverpool, UK

${ }^{2}$ Department of Paediatric Neurology, Alder Hey Children's NHS Foundation Trust, Liverpool, UK

${ }^{3}$ Institute of Infection and Global Health, University of Liverpool, Liverpool, UK

${ }^{4}$ Department of Clinical Genetics, Liverpool Women's Hospital, Liverpool, UK ${ }^{5}$ Department of Women and Children's Health, Institute of Translational Medicine, University of Liverpool, Alder Hey Children's NHS Foundation Trust, Liverpool, UK
\end{abstract}

\section{Correspondence to Dr Melissa Gladstone,} Department of Women and Children's Health, Institute of Translational Medicine, University of Liverpool, Alder Hey Children's NHS Foundation Trust, Liverpool, L14 5AB, UK; M.J.Gladstone@liverpool.ac.uk

Received 15 June 2017 Revised 20 September 2017 Accepted 21 September 2017

\section{Linked}

- http://dx.doi.org/10.1136/ archdischild-2017-312843

\section{CrossMark}

To cite: Mithyantha $R$, Kneen R, McCann E, et al. Arch Dis Child

2017;102:1071-1076.

\section{ABSTRACT}

Introduction Global developmental delay (GDD) affects $1 \%-3 \%$ of the population of children under 5 years of age, making it one of the most common conditions presenting in paediatric clinics; causes are exogenous, genetic (non-metabolic) or genetic (metabolic). Recent advances in biotechnology and genetic testing mean that the investigations available to perform for children under 5 years are increasing and are more sensitive than previously. This change in availability and type of testing necessitates an update in the recommendations for investigating GDD.

Methods We conducted a review of the literature from 2006 to 2016 to identify articles with evidence relating to the investigation of developmental delay in children under the age of 5 years. We collated the evidence into first-line and second-line investigations and, where available, on their yield and cost implications.

Results We have provided up-to-date guidance for first-line and second-line investigations for children with GDD under the age of 5 years. Recent evidence demonstrates that genetic testing for all children with unexplained GDD should be first line, if an exogenous cause is not already established. Our review of the literature demonstrates that all patients, irrespective of severity of GDD, should have investigations for treatable conditions. Evidence demonstrates that the yield for treatable conditions is higher than previously thought and that investigations for these metabolic conditions should be considered as first line. Additional second-line investigations can be led by history, examination and developmental trajectories.

Discussion We may need to update present recommendations in the UK for investigation of developmental delay. This would include microarray testing as first line and a more thorough approach to investigations for metabolic disorders that can be treated. Clinical assessment remains vital for guiding investigations.

\section{INTRODUCTION}

Global developmental delay (GDD) is defined as a delay in two or more developmental domains of gross/fine motor, speech/language, cognition, social/ personal and activities of daily living, affecting children under the age of 5 years. ${ }^{12}$ The degree of developmental delay is further subclassified as: mild (functional age $<33 \%$ below chronological age), moderate (functional age $34 \%-66 \%$ of chronological age) and severe (functional age $<66 \%$ of chronological age). ${ }^{1}$ GDD is considered significant when there is a deficit in performance of at least 2 SD below the age appropriate mean on accepted standardised assessment tests. ${ }^{3}$ With a prevalence of $1 \%-3 \%$, GDD is one of the the most common conditions encountered in paediatrics with genetic and structural brain abnormalities being the most frequent causes. ${ }^{1}$ Establishing a diagnosis enables clinicians to define treatment options and conduct surveillance for known complications as well as provide prognosis and condition-specific family support (including family planning choices). This ensures the best overall outcomes for the child and their families/carers. ${ }^{4} \mathrm{~A}$ diagnosis may also provide an explanation, a source of closure or acceptance to parents and stops clinicians advancing to potentially more expensive and invasive tests ${ }^{5-7}$

Previous estimates for the yield of investigations for GDD are broad (10\%-81\%). ${ }^{2}$ The variability may be due to differences in patient populations, clinical settings where tests are performed and the range of tests undertaken. ${ }^{2}$ The last evidencebased UK guideline for investigation of developmental delay was published 10 years ago. ${ }^{8}$ With the advent of more recent techniques in genetics and a recent burgeoning of guidelines in other countries, ${ }^{4910}$ there is a need to review our practice in the UK.

The primary objective of this paper is to provide (1) an update of the latest evidence for investigation of GDD, (2) recommendations for investigations and (3) evidence relating to yield and cost from literature presently available.

\section{METHODS}

We conducted a systematic review of the literature relating to the investigation of GDD published in the last 10 years (since the McDonald review in 2006). We searched Pubmed, Google Scholar and Embase using the MESH terms: 'developmental delay', 'developmental disorders', 'mental retardation', 'intellectual disability', 'learning disorders' AND 'guidelines' AND 'investigations'. 'Cost' and 'yield' were included along with the MESH terms. Papers included were reviews, consensus recommendations, retrospective or prospective studies. Relevant articles from reference lists were also included. We included papers published in English that were relevant to children that included investigations for GDD. We excluded papers that targeted specific metabolic, genetic or neurological conditions. We used the term GDD as meaning: delayed developmental domains in children under the age 
Table 1 Table demonstrating recommendations for first-line investigations for global developmental delay from four guidelines and our proposed recommendations

\begin{tabular}{|c|c|c|c|c|c|}
\hline Tests category & $\begin{array}{l}\text { UK current } \\
\text { McDonald et } a l^{8}\end{array}$ & UK proposed & $\begin{array}{l}\text { USA } \\
\text { Moeschler and Shevell }\end{array}$ & $\begin{array}{l}\text { Irish } \\
\text { O'Byrne et }\left.a\right|^{10}\end{array}$ & $\begin{array}{l}\text { Australian } \\
\text { Silove et a } l^{9}\end{array}$ \\
\hline Genetic & $\begin{array}{l}\text { Karyotype } \\
\text { Frag X }\end{array}$ & $\begin{array}{l}\text { Microarray } \\
\text { Frag X (selected) }\end{array}$ & $\begin{array}{l}\text { Microarray } \\
\text { Frag X }\end{array}$ & $\begin{array}{l}\text { Microarray } \\
\text { Frag X (selected) } \\
\text { Chromosomal: banded analysis } \\
\text { (selected) }\end{array}$ & $\begin{array}{l}\text { Microarray } \\
\text { Frag X }\end{array}$ \\
\hline \multicolumn{6}{|c|}{ Biochemical and metabolic } \\
\hline Blood tests & $\begin{array}{l}\text { U\&E } \\
\text { CK } \\
\text { TFT } \\
\text { Lead } \\
\text { Urate } \\
\text { FBC } \\
\text { Ferritin } \\
\text { Biotinidase }\end{array}$ & $\begin{array}{l}\text { U\&E } \\
\text { CK } \\
\text { TFT } \\
\text { Lead (If PICA) } \\
\text { FBC } \\
\text { Ferritin (dietary restriction) } \\
\text { AA } \\
\text { Homocysteine } \\
\text { Acylcarnitine profile }\end{array}$ & $\begin{array}{l}\text { TFT } \\
\text { Lead (selected) } \\
\text { AA } \\
\text { Homocysteine } \\
\text { Acylcarnitine profile }\end{array}$ & $\begin{array}{l}\text { U\&E } \\
\text { CK } \\
\text { TFT } \\
\text { LFT } \\
\text { FBC } \\
\text { Bone profile } \\
\text { Urate } \\
\text { Glucose, lactate } \\
\text { Venous blood gas } \\
\text { AA } \\
\text { Homocysteine } \\
\text { (selected if raised methionine) }\end{array}$ & $\begin{array}{l}\text { U\&E } \\
\text { CK } \\
\text { TFT } \\
\text { FBC } \\
\text { Lead } \\
\text { AA }\end{array}$ \\
\hline Urine tests & & $\begin{array}{l}\text { OA } \\
\text { GAG } \\
\text { Oligosaccharides } \\
\text { Creatine/GAA } \\
\text { Purine and pyramidines }\end{array}$ & $\begin{array}{l}\text { OA } \\
\text { GAG } \\
\text { Oligosaccharides } \\
\text { Creatine/GAA } \\
\text { Purine and pyramidines }\end{array}$ & $\begin{array}{l}\text { OA } \\
\text { GAG } \\
\text { Paired urate } \\
\text { +Urate/creatinine }\end{array}$ & $\begin{array}{l}\text { OA } \\
\text { GAG }\end{array}$ \\
\hline
\end{tabular}

AA, amino acids; ASD, autistic spectrum disorder; CK, creatine kinase; FBC, full blood count; Frag X, fragile X; GAG, glycosaminoglycans; LFT, liver function test; OA, organic acids; TFT, thyroid function tests; U\&E, urea and electrolytes.

of 5 years and intellectual disability (ID) as the term used after this age when IQ can be reliably tested. ${ }^{11}$

For this review, we discuss and categorise investigations into first-line and second-line tests and subcategorised them to genetics, metabolic and imaging. See table 1 for recommended first-line investigations to be considered prior to referral to specialist services. We show a flowchart and decision-making tree for investigations in figure 1.

\section{FIRST-LINE ASSESSMENT AND INVESTIGATIONS History and examination}

Comprehensive clinical assessment remains the core to planning investigations in young children presenting with GDD. ${ }^{4-10}$ Aetiology can be categorised into exogenous, genetic (non-metabolic) and genetic (metabolic). ${ }^{11}$ The diagnosis of exogenous causes includes teratogenic agents (alcohol and drugs); prenatal,

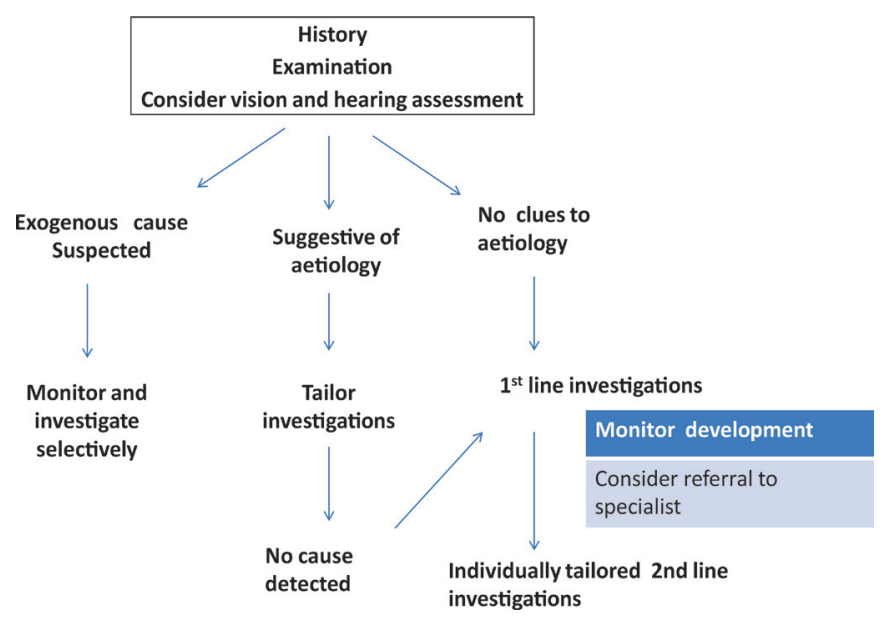

Figure 1 Flow chart for decision making for investigations for global developmental delay in young children. perinatal causes (prematurity, infections); and social causes often best assessed by history but must not be assumed.

Investigations following a thorough clinical history (including a family pedigree, pregnancy and birth history) and a detailed physical examination by a trained specialist lead to a higher diagnostic yield. ${ }^{312}$ Identification and correction of sensory deficits are essential, while evaluating these children and may provide pointers to the underlying aetiology. ${ }^{26}$

An examination of the child's developmental status in all domains (gross motor, fine motor, language, socioemotional and cognitive skills) using a recognised tool to provide a normative comparison should also be conducted. Repeated clinical/dysmorphology and developmental assessments over time are more informative than one-off assessments in planning investigations and management.

It is important that the clinician consider investigations in all levels of developmental delay including those with persistent mild GDD, given the variable phenotypic presentations of genetic and metabolic conditions. Some studies, although from tertiary centres, have found that severity did not impact on the diagnostic rate of investigations, ${ }^{12}$ while others report higher yield in patients with moderate-to-severe GDD. ${ }^{13}$ Serial assessment enables clinicians to identify changing phenotypes over time. When metabolic conditions are clinically suspected, annual evaluation after the first year of life until school age is recommended. ${ }^{14}$

Some studies have demonstrated that we can identify the cause of developmental or cognitive delay in a one-third of cases by history and examination alone. With clinical evaluation prompting investigations, we can identify another one-third. It is only the latter one-third that are identified by investigations only. ${ }^{12}$ The presence of abnormal neurology, microcephaly, female gender, dysmorphism, abnormal prenatal or perinatal history and absence of autistic features are linked with higher aetiological yield of investigations. ${ }^{15}$ Investigations following comprehensive clinical evaluation are also cost effective. ${ }^{16}$ 


\section{Genetic testing}

First-line tests

Genetic investigation by means of standard karyotyping was recommended as a first-line investigation in the UK guidance from $2006 .^{8}$ The implementation of 'molecular karyotyping' or chromosome microarray (array-based comparative genomic hybridisation $(\mathrm{aCGH})$ ) has changed the state of play. Recent evidence-based international guidelines promote the use of aCGH as a first-tier investigation for GDD if no aetiological indicators from history and examination are found. ${ }^{4} 10$ The higher sensitivity that it has for identifying submicroscopic deletions and duplications (than standard karyotyping methods) and better definition of the breakpoints and size of imbalances all make microarray a suitable first-line test. ${ }^{4} 1718$

Chromosome microarray has been described to be the 'single most efficient diagnostic test' for GDD after history and examination. ${ }^{4} \mathrm{~A}$ literature search of 33 studies that used this technique in nearly 22000 patients has demonstrated that the diagnostic yield of aCGH is between $15 \%$ and $20 \%$, while karyotyping is $3 \%{ }^{18}$ The diagnostic yield of microarray is supported by a health economics report, which showed cost saving when comparing a National Health Service (NHS) clinical genetics service use of aCGH as a first-tier test while evaluating learning disability, compared with $\mathrm{CGH}$ as second line after negative karyotyping. ${ }^{19}$

Molecular karyotyping will not detect conditions where structural changes in the chromosomes result in no loss or gain of genetic material such as balanced translocations or inversions, ring chromosomes and low-level mosaicism. ${ }^{18}$ 20 A standard karyotype is still required if such a disorder is suspected (eg, refractory epilepsy, if a family is known to have a balanced translocation associated with a phenotype, a history of multiple miscarriages or clinical features to suggest mosaicism). Syndromes caused by methylation defects (eg, Beckwith-Wiedemann, Angelman syndrome) or mutations in single genes will also go undetected unless specifically tested.

Fragile $\mathrm{X}$ syndrome affects approximately 1/5000 births, typically causing moderate ID in boys and a variable phenotype in girls (unaffected to significant). Phenotypic features evolve and are not as apparent in younger children. ${ }^{9}$ The UK genetic testing network and international guidelines therefore do promote testing for fragile $\mathrm{X}$ for children with moderate-to-severe GDD, without profound physical disability, as an additional first-tier genetic investigation. ${ }^{491021}$ Testing criteria are available to help aid clinical decisions in older children. ${ }^{21}$

\section{Second-line tests}

Clinical syndromes can present with variable phenotypes, and children who have a normal aCGH and FMR1 may be best assessed by a clinical geneticist to ensure that the most appropriate and cost-effective additional tests are undertaken. ${ }^{22}$ Use of specific gene tests such as those for Rett syndrome (or its variants) or gene panels for ID has been proposed as second-line tests. ${ }^{4}$ There is an increasing number of panels and exome sequencing tests available for ID (UK Genetic Testing Network; http://www. ukgtn.nhs.uk) or private providers, but specialist services (clinical genetics or paediatric neurology) do most requests for these tests, although this is likely to change as mainstreaming of these investigations advances.

\section{Metabolic and biochemical investigations}

There is limited good quality evidence for first-line metabolic investigations. Recommendations from Ireland are based on evidence review by expert committee, ${ }^{10}$ while those from
Australia are based on a literature review, quoting grade III-IV evidence. $^{9}$

Inborn errors of metabolism (IEMs) are rare, their prevalence likely to vary in different populations. There is limited UK data on detecting metabolic disorders in patients with GDD. ${ }^{14}$ IEMs are usually associated with systemic features, and previous guidelines recommend selective metabolic investigations. ${ }^{28}$ Some IEMs are now (partially) treatable, and for others, treatment is in the research stages. Treatment includes dietary supplements (folinic acid for cerebral folate deficiency, pyridoxine or pyridoxal phosphate for B6-responsive epilepsy, creatine in creatine transporter deficiency, uridine in pyrimidine 5-nucleotidase super activity), dietary restriction (homocystinuria, glutaricacidaemia) and ketogenic diet (pyruvate dehydrogenase deficiency, Glut 1 transporter deficiency). Other treatments include: haematopoietic stem cell transplantation (mucopolysaccharidoses, metachromatic leucodystrophy), enzyme replacement (Fabry's disease, Gaucher's disease, neuronal ceroid lipofuscinosis) or gene therapy (adrenoleucodystophy, lysosomal storage disorders). ${ }^{23-25}$

A systematic review of literature by van Karnebeek et al identified 89 conditions presenting with ID as a major feature, which are susceptible to treatment. Of these, $60 \%$ could be identified by non-targeted urine and blood tests. Some of these conditions (eg, creatine transporter defects, mild homocystinuria, female ornithine transcarbamylase deficiency) can initially present as GDD alone. $^{2526}$ While individual treatable IEMs are extremely rare in the general population, the prevalence will be higher in the at-risk population. Hence, though small in number, these treatable causes of GDD have been the focus of the more recent US guidance, with recommendations that screening for IEM should be used in all patients with GDD of unknown aetiology. ${ }^{4} 24 \mathrm{~A}$ list of tests with treatable conditions they identify is shown in table 2 .

The neonatal screening programme in the UK (Guthrie test) currently includes six IEMs (phenyketonuria, medium-chain acyl-CoA dehydrogenase deficiency, maple syrup urine disease, isovaleric acidaemia, glutaricaciduria type 1, homocystinuria (pyridoxine unresponsive)) and congenital hypothyroidism. It is restricted when compared with other countries (eg, Canada, the USA, The Netherlands), which offer a wider range including urea cycle disorders, organic and some amino acid disorders. Testing for these is, therefore, more relevant in UK patients with GDD, and IEMs should be considered in symptomatic children. ${ }^{14}$

There are also some conditions where early diagnosis can be made from simple and cheap biochemical screening tests. This includes creatine kinase and thyroid function tests as well as ferritin, vitamin B12 and lead on a selective basis when Pica, dietary restrictions (vegan diet in child/mother) or environmental exposure risk is possible. ${ }^{9}$ While these tests seldom lead to a diagnosis, they also may add to a diagnosis (eg, macrocytic anaemia in organic acidaemias, abnormal triiodothyronine in Allan-Herdon-Dudley syndrome). ${ }^{1027}$

There is limited research on comprehensive metabolic evaluation in larger groups of individuals with GDD. It is, therefore, difficult to estimate the yield of many of the proposed first-line metabolic tests. A recent systematic review conducted for the American Academy of Neurology found that yield of metabolic investigations varied between $0.2 \%$ and $4.6 \%$, based on clinical signs and range of tests undertaken in the studies (grade III evidence) ${ }^{28}$ Second-line individually tailored testing in a tertiary setting in the Netherlands produced an overall yield of $2.8 \%$ for metabolic investigations. ${ }^{11}$

Individually tailored second-line testing ${ }^{4} 1426$ and referral to a specialist service is recommended, ${ }^{49}$ when clinical suspicion 


\begin{tabular}{|c|c|}
\hline $\begin{array}{l}\text { Test } \\
\text { (number of conditions } \\
\text { identified) }\end{array}$ & Conditions identified \\
\hline Plasma amino acids, $\mathrm{n}=13$ & $\begin{array}{l}\text { I.o. argininemia, I.o. argininosuccinic aciduria } \\
\text { I.o. citrullinemia , I.o. citrullinemia type II } \\
\text { CPS deficiency, HHH syndrome } \\
\text { Maple syrup urine disease (variant) } \\
\text { I.o. NAGS deficiency, OTC deficiency } \\
\text { Phenylketonuria, tyrosinemia type II } \\
\text { MTHFR deficiency, PDH complex deficiency }\end{array}$ \\
\hline Plasma total homocysteine, $n=7$ & $\begin{array}{l}\text { Cobalamin C, D, E, F and G deficiencies } \\
\text { Homocystinuria, MTHFR deficiency }\end{array}$ \\
\hline Acylcarnitine, $n=7$ & $\begin{array}{l}\text { Ethylmalonic encephalopathy } \\
\text { Isovaleric acidemia, tyrosinemia type II } \\
\text { Cobalamin C, D and F deficiencies, } \\
\text { 3-methylcrotonyl glycinuria }\end{array}$ \\
\hline Urine organic acid, $n=22$ & $\begin{array}{l}\text { B-Ketothiolase deficiency, MHBD deficiency } \\
\text { Cobalamin A, B, C, D and F deficiencies } \\
\text { Glutaric acidemia I, glutaric acidemia II } \\
\text { HMG-CoA lyase deficiency, tyrosinemia type II } \\
\text { Holocarboxylase synthetase deficiency } \\
\text { 3-Methylglutaconic aciduria, 3-methylylcrotonyl } \\
\text { glyciuria } \\
\text { Methylmalonic acidemia, isovaleric acidemia } \\
\text { Homocystinuria, propionic acidemia mHMG-CoA } \\
\text { synthase deficiency } \\
\text { SCOT deficiency, SSADH deficiency }\end{array}$ \\
\hline Glycosaminoglycans, $n=4$ & $\begin{array}{l}\text { Hunter syndrome (MPS II) } \\
\text { Hurler syndrome (MPS I) } \\
\text { Sanfilippo syndrome A, B, C } \\
\text { Sly syndrome (MPS VII) }\end{array}$ \\
\hline Purines and pyramidines, $n=3$ & $\begin{array}{l}\text { Molybdenum cofactor deficiency type A } \\
\text { Pyrimidine 5-nucleotidase superactivity } \\
\text { Lesch-Nyhan syndrome }\end{array}$ \\
\hline Oligosaccharides, $\mathrm{n}=2$ & $\begin{array}{l}\alpha \text {-Mannosidosis } \\
\text { Aspartylglucosaminuria }\end{array}$ \\
\hline Urine creatine metabolites, $n=3$ & $\begin{array}{l}\text { AGAT deficiency } \\
\text { Creatine transporter defect } \\
\text { GAMT deficiency }\end{array}$ \\
\hline
\end{tabular}

Adapted from Van Karnebeek. ${ }^{25}$ Some conditions are identified by more than one test.

AGAT, arginine: glycine amidinotransferase; CPS, carbamoyl phosphate synthetase; GAMT, guanidino-acetate- $\mathrm{N}$-methyltransferase; $\mathrm{HHH}$, hyperornithinemia, hyperammonemia, homocitrullinemia; HMG-CoA, 3-hydroxy-3-methylglutarylCoA; I.o., late-onset form; MHBD, 2-methyl-3-hydroxybutyryl-CoA dehydrogenase; mHMG CoA, mitochondrial 3-hydroxy-3-methylglutaryl-CoA; MTHFR, methylenetetrahydrofolate reductase; NAGS, $\mathrm{N}$-acetylglutamate synthetase; OTC, ornithine transcarbamylase; PDH, pyruvate dehydrogenase; SCOT, succinyl $\mathrm{CoA}$ 3-oxoacid CoA transferase; SSADH, succinic semialdehyde dehydrogenase.

remains. An evidence-based, free web-based application (http:// www.treatable-id.org) may be useful to tailor investigations for treatable IEMs not covered by first-line tests. ${ }^{29}$

\section{Neuroimaging}

MRI of the brain has been used selectively and non-selectively in evaluating patients with GDD. The diagnostic yield of MRI is higher when used in patients where GDD is associated with clinical signs such as abnormal head circumference (microcephaly, non-familial macrocephaly, rapid change in head circumference), focal neurological signs or epilepsy. Targeted imaging was hence advocated by previous guidelines. ${ }^{28}$ Previous studies have demonstrated abnormal results in targeted imaging in about $41 \%$ compared with $14 \%$ with non-selective screening. ${ }^{3}$ Recent studies continue to demonstrate higher abnormality detection rates when MRI is performed in patients with GDD with additional clinical/neurological signs. ${ }^{3031}$ More complex MRI protocols (eg, proton magnetic resonance spectroscopy) are promising tools to investigate GDD and enable a non-invasive measure of brain metabolites such as lactate or white matter choline, ${ }^{32}$ but studies have so far failed to show an increased diagnostic yield, ${ }^{3133}$ and hence these are best used as second line in selected patients.

MRI is a more sensitive test and has no radiation exposure, making it a preferred choice over CT. However, all children under 5 years will need sedation or a general anaesthetic, which has a slim risk attached, and some children will need further investigations including a lumbar puncture. There is an argument, therefore, that children requiring brain imaging should see a specialist prior to imaging, if an anaesthetic is required.

\section{Special considerations \\ Regression}

A child where there is concern about regression in skills should be referred for an assessment from a specialist in neurodisability or neurology. True regression is quite rare, but incidence can vary with ethnic background of the local population. It can be difficult to establish if there is true regression or if the child has an evolution of their static disorder. Sometimes a child with GDD can demonstrate pseudo-regression where the gap in intellectual abilities between them and their peers is widening or in a child with cerebral palsy (CP) who has rapid growth and who may experience a decline in the motor function. The development of epilepsy can also impact on cognitive or behavioural function, especially in those with pre-existing GDD, autistic spectrum disorder or CP. Some children with regression may have a stepwise deterioration in function associated with decompensation (often an encephalopathy). This clinical pattern points to energy failure, and mitochondrial disorders should be suspected. A full discussion about genuine regression is beyond the scope of this article. However, the recent progressive intellectual and neurological deterioration study (www.rcpch.ac.uk/pind) has provided excellent data about more common causes (box). ${ }^{34}$ Some disorders that cause regression may be amenable to treatment or be eligible for a treatment trial. It is important, therefore, that the general paediatrician should have an awareness of the presentation of these disorders.

Children that should be referred to a specialist in neurodisability or neurology are shown on table 3 . Investigations should

\section{Box Ten most common causes of progressive intellectual and neurological deterioration}

10 most common causes of PIND reported in the PIND study in the UK (www.rcpch.ac.uk/pind) ${ }^{34}$

- NCL late infantile

- Mucopolysaccharidosis IIIA (San Filippo)

- Rett syndrome

- Metachromatic leucodystrophy

- Adrenoleucodystrophy

- NCL juvenile

- GM2 gangliosidosis type 1 (Tay-Sachs)

- Niemann-Pick type C

- Krabbe

- GM2 gangliosidosis type 2 (Sandhoff)

$\mathrm{NCL}$, neuronal ceroid lipofuscinosis; PIND, progressive intellectual and neurological deterioration. 
Table 3 Clinical pointers to consider referral to a specialist in neurodisability or neurology

\begin{tabular}{ll}
\hline Features in the history & Regression or possible regression including significant change in behaviour \\
& Possible or definite seizures \\
& Movement disorder: continuous or paroxysmal \\
& Muscle pain/fatigue \\
& New onset sensory impairment, for example, significant decline in visual acuity \\
& Cognitive decline/behavioural change in a child with epilepsy or ASD \\
Examination findings & Neurological signs: dystonia, ataxia, movement disorder, for example, chorea, focal signs, cranial nerve signs, muscle weakness/signs of a peripheral \\
& neuropathy, arthrogryposis/joint contractures, CP picture without a clear cause/history \\
& Ocular signs: nystagmus, eye movement disorder, abnormal fundi, cataract \\
& Other signs: sensorineural deafness \\
& Neurocutaneous features \\
& Organomegaly/cardiomegaly \\
Course or dysmorphic facial features
\end{tabular}

CP, cerebral palsy.

be individualised and targeted as they can be invasive (eg, LP, muscle/skin biopsy) or painful (eg, nerve conduction studies and electromyography) and are expensive and time consuming for medical staff and families. Children with regression may also be referred to the clinical genetics team where specific next-generation sequencing panels can be undertaken and, at present, considered for the 100000 Genome Project (www.genomicsengland.co.uk/the-100000-genomes-project).

\section{Immigrant children}

Immigrant children are exposed to a combination of biological, socioeconomical, emotional and environmental adverse events placing them at higher risk of developmental problems. This includes malnutrition and disability from trauma, overcrowding and toxin exposure and loss of parents or trauma from lack of stability. ${ }^{35}$ Furthermore, children may have missed new-born screens and vaccinations and been exposed to infectious diseases. In these children, comprehensive clinical assessments should consider all these factors while planning individual investigations.

\section{DISCUSSION}

Despite new advances in technology, particularly in the realm of genetic investigation, clinical assessment continues to be vital in guiding investigation. Clues to investigation may lie in the history and examination with clinical judgement being essential to enabling the right pathways to be taken in making a diagnosis. A good history can help direct which route to take in terms of investigation, particularly when exogenous causes are identified. Assessment over a period will provide clarity as to whether a condition is resolving, static or deteriorating. Assessment over time enables the phenotype to evolve and more appropriate targeting of investigations.

It is clear that establishing a diagnosis enables us to answer questions on: why it has happened (aetiology), what does it mean for our child (prognosis), what treatments might be available (precision medicine) and whether it can be prevented in the future (prenatal testing and preimplantation genetic diagnosis).

In these recommendations, we have also highlighted the recent evidence that promotes metabolic screening tests to detect treatable conditions. This is a move away from older guidance where metabolic investigations were not recommended for children with no features/risk factors other than GDD. ${ }^{2}$ Though rare, the possibility of presentation as stable developmental delay and potential for treatment merits their inclusion as first-line tests. Treatment outcomes vary but can potentially improve cognitive development, slow deterioration, prevent metabolic decompensation and improve seizure control and systemic manifestations. $^{25} 26$

GDD and ID affect 2\%-3\% of the worldwide population with a lifetime cost of up to US\$1 million. ${ }^{36}$ First-line metabolic investigations to identify treatable IEMs cost approximately $\$ C 568,{ }^{26}$ with costs in Ireland for all first-line tests at $€ 1335 . .^{10}$ Costs in the UK NHS laboratory for aCGH are not astronomical ( $£ 338$ $£ 350),{ }^{3738}$ with the majority of combined metabolic tests costing under $£ 1000 .^{38}$ Not all children will get a diagnosis and cost per diagnosis may be high, but there are obvious long-term cost savings if early diagnosis and treatment are possible. The options of genetic counselling and support for young families also make diagnosis invaluable.

Recent advances in genomic medicine are transforming the investigation of children with significant developmental delay and are likely to transform the way we assess and investigate children. Traditional models of care have relied on history and examination with broad and then specific investigations to funnel down to specific diagnoses. The advent of rapid genetic testing and 'omic' medicine is likely to turn this paradigm on its head with whole genome/exome sequencing identifying genes, which may be causing the phenotype in an individual. The clinician will then use knowledge of their patient to make a judgement about whether this is the cause for their patient-'reverse dysmorphology'.

These advances in genomic medicine will lead to an increase in diagnoses that will modify how the individual is clinically cared for (precision medicine). The Deciphering Developmental Disorders study and the 100000 Genome Project will both aid our understanding of disorders. We predict that, with time, whole genome sequencing/exome sequencing may become the first-line investigation of choice for all children with unexplained GDD and that other investigations will be secondary to this and used primarily for phenotyping. These will provide answers for families about the underlying cause of their child's condition and will prevent further costly and potentially distressing investigations taking place.

\section{CONCLUSIONS}

In this paper, we have outlined the present evidence and recommendations for both first-line and second-line investigations for GDD in children in the UK. We have provided new evidence relating to the use of genetic testing techniques and have demonstrated that this should be a first-line investigation for all children with GDD. Second to this, any treatable metabolic 
conditions should be always considered. With time, it is likely that the investigation of children with developmental delay will be turned on its head and we will be going from genetic diagnosis to phenotypic diagnosis. Despite this, history and examination will always be crucial for defining the condition and the change over time.

Contributors RM, RK, EM and MG contributed to the initial idea for the paper, wrote and reviewed sections of the paper and approved the final version. RM conducted the literature review with the support of MG and wrote the first draft of the paper.

Funding None declared.

Competing interests None declared.

Provenance and peer review Commissioned; externally peer reviewed.

Open Access This is an Open Access article distributed in accordance with the Creative Commons Attribution Non Commercial (CC BY-NC 4.0) license, which permits others to distribute, remix, adapt, build upon this work non-commercially, and license their derivative works on different terms, provided the original work is properly cited and the use is non-commercial. See: http://creativecommons.org/ licenses/by-nc/4.0/

(c) Article author(s) (or their employer(s) unless otherwise stated in the text of the article) 2017. All rights reserved. No commercial use is permitted unless otherwise expressly granted.

\section{REFERENCES}

1 Majnemer A, Shevell MI. Diagnostic yield of the neurologic assessment of the developmentally delayed child. J Pediatr 1995;127:193-9.

2 Shevell M, Ashwal S, Donley D, et al.Practice parameter: evaluation of the child with global developmental delay: report of the quality standards subcommittee of the american academy of neurology and the practice committee of the child neurology society. Neurology 2003;60:367-80.

3 Shevell MI, Majnemer A, Rosenbaum P, et al. Etiologic yield of subspecialists' evaluation of young children with global developmental delay. J Pediatr 2000;136:593-8.

4 Moeschler JB, Shevell M.Comprehensive evaluation of the child with intellectual disability or global developmental delays. Pediatrics 2014;134:e903-e918.

5 Shonkoff JP, Hauser-Cram P. Early intervention for disabled infants and their families: a quantitative analysis. Pediatrics 1987;80:650-8.

6 Baird G, McConachie H, Scrutton D. Parents' perceptions of disclosure of the diagnosis of cerebral palsy. Arch Dis Child 2000;83:475-80.

7 Hayeems RZ, Babul-Hirji R, Hoang N, et al. Parents' experience with pediatric microarray: transferrable lessons in the era of genomic counseling. J Genet Couns 2016:25:298-304.

8 McDonald L, Rennie A, Tolmie J, et al. Investigation of global developmental delay. Arch Dis Child 2006;91:701-5.

9 Silove N, Collins F, Ellaway C. Update on the investigation of children with delayed development. J Paediatr Child Health 2013:49:519-25.

10 O'Byrne JJ, Lynch SA, Treacy EP, et al. Unexplained developmental delay/learning disability: guidelines for best practice protocol for first line assessment and genetic/ metabolic/radiological investigations. Ir J Med Sci 2016;185:241-8.

11 Engbers HM, Berger $R$, van Hasselt $P$, et al. Yield of additional metabolic studies in neurodevelopmental disorders. Ann Neurol 2008;64:212-7.

12 van Karnebeek CD, Scheper FY, Abeling NG, et al. Etiology of mental retardation in children referred to a tertiary care center: a prospective study. Am J Ment Retard 2005; 110:253-67.

13 Wong VC, Chung B. Value of clinical assessment in the diagnostic evaluation of Global Developmental Delay (GDD) using a likelihood ratio model. Brain Dev 2011:33:548-57.
14 Cleary MA, Green A. Developmental delay: when to suspect and how to investigate for an inborn error of metabolism. Arch Dis Child 2005;90:1128-32.

15 Srour M, Mazer B, Shevell MI. Analysis of clinical features predicting etiologic yield in the assessment of global developmental delay. Pediatrics 2006;118:139-45.

16 Duker AL, Teed LN, Thomas RL, et al. 'The cost and yield of evaluations for developmental delay/mental retardation'. Dev Med Child Neurol 2008;50:798-9.

17 Srour M, Shevell M. Genetics and the investigation of developmental delay/intellectual disability. Arch Dis Child 2014;99:386-9.

18 Miller DT, Adam MP, Aradhya S, et al. Consensus statement: chromosomal microarray is a first-tier clinical diagnostic test for individuals with developmental disabilities or congenital anomalies. Am J Hum Genet 2010;86:749-64.

19 Sagoo G, Mohammed S. Array CGH for learning disability - when is it worth it? : PHG Foundation.

20 Kharbanda M, Tolmie J, Joss S. How to use microarray comparative genomic hybridisation to investigate developmental disorders. Arch Dis Child Educ Pract Ed 2015; 100:24-9.

21 Lunt P. Testing criteria for fragile X syndrome: report of the outcome from the UKGTN fragile $X$ workshop. London: UK Genetic Testing Network.

22 Flore LA, Milunsky JM. Updates in the genetic evaluation of the child with global developmental delay or intellectual disability. Semin Pediatr Neurol 2012;19:173-80.

23 Arias A, Corbella M, Fons C, et al. Creatine transporter deficiency: prevalence among patients with mental retardation and pitfalls in metabolite screening. Clin Biochem 2007:40:1328-31.

24 van Karnebeek CD, Stockler IS. Evidence-based approach to identify treatable metabolic diseases causing intellectual disability. 2011.

25 van Karnebeek CD, Stockler S. Treatable inborn errors of metabolism causing intellectual disability: a systematic literature review. Mol Genet Metab 2012:105:368-81.

26 van Karnebeek CD, Shevell M, Zschocke J, et al. The metabolic evaluation of the child with an intellectual developmental disorder: diagnostic algorithm for identification of treatable causes and new digital resource. Mol Genet Metab 2014;111:428-38.

27 Galloway P. Best practice guidelines for the biochemical livestigation of global developmental delay for Inherited Metabolic Disorders (IMD). 28-1-2013: national metabolic biochemistry network, 2013.

28 Michelson DJ, Shevell MI, Sherr EH, et al. Evidence report: genetic and metabolic testing on children with global developmental delay: report of the quality standards subcommittee of the american academy of neurology and the practice committee of the child neurology society. Neurology 2011;77:1629-35.

29 Sayson B, Popurs MA, Lafek M, et al. Retrospective analysis supports algorithm as efficient diagnostic approach to treatable intellectual developmental disabilities. $\mathrm{Mol}$ Genet Metab 2015:115:1-9.

30 Griffiths PD, Batty R, Warren D, et al. The use of MR imaging and spectroscopy of the brain in children investigated for developmental delay: what is the most appropriate imaging strategy? Eur Radiol 2011;21:1820-30.

31 Verbruggen KT, Meiners LC, Sijens PE, et al. Magnetic resonance imaging and proton magnetic resonance spectroscopy of the brain in the diagnostic evaluation of developmental delay. Eur J Paediatr Neurol 2009;13:181-90.

32 Verbruggen KT, Maurits NM, Meiners LC, et al. Quantitative multivoxel proton spectroscopy of the brain in developmental delay. J Magn Reson Imaging 2009:30:716-21.

33 Martin E, Keller M, Ritter S, et al. Contribution of proton magnetic resonance spectroscopy to the evaluation of children with unexplained developmental delay. Pediatr Res 2005:58:754-60.

34 Verity C, Winstone AM, Stellitano L, et al. The epidemiology of progressive intellectual and neurological deterioration in childhood. Arch Dis Child 2010;95:361-4.

35 Davidson N, Skull S, Chaney G, et al. Comprehensive health assessment for newly arrived refugee children in Australia. J Paediatr Child Health 2004:40:562-8.

36 Centers for Disease Control and Prevention (CDC). Economic costs associated with mental retardation, cerebral palsy, hearing loss, and vision impairment--United States, 2003. MMWR Morb Mortal Wkly Rep 2004;53:57-9.

37 Great Ormond Street Hospial for Children NHS Foundation Trust,North East Thames Regional Genetics Service. Pricing, 2014

38 Community Children's Health Partnership. Investigations for developmental delay: blood tests costs (2014) and what results could indicate? 2014. 